\title{
Mais um ano da Revista de Terapia Ocupacional, avanços e perspectivas
}

Finalizamos o ano de 2013 com a publicação deste fascículo!

Agradecemos imensamente aos autores, colaboradores, leitores e todos os parceiros que tem contribuído, confiado no trabalho da Revista e apostado no projeto de consolidação científica da Terapia Ocupacional no Brasil.

Agradecimentos especiais á atual jovem equipe da Secretaria Executiva e ao grupo de bibliotecárias que, com dedicação e empenho tem navegado nas marés, nada tranquilas, que ainda nos surpreendem. As dificuldades ainda são muitas, mas nossa conclusão é de que tem valido a pena.

Colaboram neste fascículo docentes e pesquisadores das Universidades: Universidade Estadual de Ciências da Saúde de Alagoas (UECSAL); Universidade Federal de São Paulo (UNIFESP); Universidade Federal de Minas Gerais (UFMG); Universidade Federal de Pernambuco (UFPE); Universidade Federal de São Carlos (UFSCAR); Universidade Federal do Espirito Santo ( UFES); Universidade Federal do Pará (UFPA); Universidade Federal do Triangulo Mineiro (UFTM); Universidade São Paulo Ribeirão, (USPRP).

Trabalhos de qualidade, muitos deles de caráter interdisciplinar e interprofissional, resultados de teses de doutorado, dissertação de mestrado, monografias de conclusão de curso e projetos de grupos de pesquisa, que mostram a importância da ampliação do ensino público e das Universidades de pesquisa para a área.

Artigos abordando temáticas atuais e relevantes na área de saúde mental ganharam destaque neste número, o que nos remete ao importante papel de pesquisadores e profissionais da terapia ocupacional na construção da Política Nacional de Saúde Mental e no novo paradigma Psicossocial.

Boa leitura!

Elisabete Ferreira Mângia

Selma Lancman

Editoras da Revista de Terapia Ocupacional da USP 